\title{
Environmentally Friendly Composite Film of Anodizing and Electrodeposition Coating Having a High Corrosion Resistance on Magnesium Alloy AZ91D
}

\author{
Masaaki Hara $^{1}$, Kenji Matsuda ${ }^{1}$, Wataru Yamauchi ${ }^{1}$, Masaaki Sakaguchi ${ }^{2}$, \\ Toshiyuki Yoshikata ${ }^{2}$, Yorinobu Takigawa ${ }^{3}$ and Kenji Higashi ${ }^{3}$ \\ ${ }^{1}$ SHIMANO Inc., Sakai 590-8577, Japan \\ ${ }^{2}$ Okuno Chemical Industries Co. Ltd., Osaka 538-0044, Japan \\ ${ }^{3}$ Department of Materials Science, Graduate School of Engineering, Osaka Prefecture University, Sakai 599-8531, Japan
}

\begin{abstract}
In this study, we compared and examined the corrosion resistance of the magnesium alloy with the composite film of 2 kinds of coating on 3 kinds of surface treated film as the substrate treatment. 3 kinds of surface treated film stands for conventional DOW17 anodized film (DAF), chemical conversion treatment JISA3-type MX3 film (CCF), which contain hexavalent chromium, fluorine and phosphorus compounds, and environmentally friendly silicate anodized film (SAF) containing no hazardous substances and 2 kinds of coating stands for organic coating and electrodeposion coating. As a result of the analysis, we could observe that it was extremely effective for magnesium alloy AZ91D to apply the composite film of environmentally friendly SAF with cationic electrodeposition coatings to obtain superior corrosion resistance to that of the composite film of conventional DAF or CCF with organic spray coating. At the same time we could take an action for the environment countermeasure by using the environmentally friendly SAF with the water base cationic electrodeposition coatings as a countermeasure for VOC (Volatile Organic Compound) regulations. [doi:10.2320/matertrans.MRA2006632]
\end{abstract}

(Received November 22, 2006; Accepted September 20, 2007; Published November 7, 2007)

Keywords: magnesium alloy, anodizing, cationic electrodeposition coating, organic spray coating, corrosion resistance

\section{Introduction}

In recent years, in accordance with the rapid increase in demand for higher performance, compactness and reduced weight for electrical home appliances, automotive parts, outdoor products and others, the application of magnesium alloy has been increasing. Consequently, surface treatment methods have been devised according to usage conditions and the environment, ${ }^{1)}$ and various research has been taking place on surface treatments to provide higher and better corrosion resistance and wear resistance. ${ }^{2)}$

As the surface treatment of magnesium alloy today, although an organic spray coating is applied without any substrate treatment for coating for certain application conditions, organic spray coating is normally applied after chemical conversion treatment. ${ }^{3-6)}$ However, in the case of sporting goods and others, used within a severe outdoor environment, a higher corrosion resistance than the current combination of chemical conversion treatment with organic spray coating is required. Under these circumstances, and to provide products with higher added value, it is essential to provide higher corrosion resistance on even articles having irregular complex shapes besides the design. Therefore, we consider the optimum treatment method to be the composite treatment of anodizing for over $10 \mu \mathrm{m}$ of economical passive film, in place of conventional thin film chemical conversion as a substrate treatment, and on it, apply electrodeposition coating which is economical and has good covering power. ${ }^{7-10)}$ In our previous paper, ${ }^{11)}$ as an environmental measure, we reported an environmentally friendly and excellent corrosion resistant SAF which did not contain any hazardous substances, unlike DAF and $\mathrm{CCF}$ containing hexavalent chromium as well as fluorine and phosphorus compounds.

With reference to the coating, in response to recent VOC regulatory measures, although high solid type paints, water- based paints, powder paints and solvent-free liquid paints have been tried as coatings, ${ }^{12)}$ we consider electrodeposition coating to be the most suitable with practical applications, such as coating efficiency, film thickness uniformity on irregular complex shapes, cost reduction and mass-productivity in mind. We believe the composite film of environmentally friendly $\mathrm{SAF}^{13-15)}$ with environmentally friendly electrodeposition coating to be the optimum treatment. Though many studies on the corrosion mechanism of magnesium alloys in the natural environment, and the chemical conversion treatment and anodizing themselves have been reported, ${ }^{16-31)}$ relatively little research has been reported on the influence of the anodizing film of the magnesium alloy on electrodeposition coating film, and research on the corrosion resistance of the composite film of anodizing with electrodeposition coating. ${ }^{32,33)}$

In this study, as the substrate treatment for AZ91D diecasting material, which is a magnesium alloy, with high application and considerable strength, we applied the abovementioned environmentally friendly silicate-based anodizing, the typical anodizing treatment DOW17 anodizing and the JIS3-type MX (H8652) treatment which offered optimum corrosion resistance among the chemical conversion methods, applied cationic electrodeposition coating or organic spray coating on these substrate treatments and also applied a comparison test of corrosion resistance by the CASS (Copper Accelerated Acetic Acid Salt Spray) Test. We also studied the corrosion resistance of the anodizing films by DOW17 anodizing and silicate-based anodizing as substrate treatments from the electrochemical perspective. ${ }^{34)}$

\section{Experimental}

\subsection{Preparation of specimens}

As the test specimen, the magnesium alloy AZ91D diecasting material shown in Table 1 was used. Specimens were 
Table 1 Chemical composition of AZ91D.

\begin{tabular}{ccccccccc}
\hline Wt\% & $\mathrm{Al}$ & $\mathrm{Zn}$ & $\mathrm{Si}$ & $\mathrm{Mn}$ & $\mathrm{Fe}$ & $\mathrm{Cu}$ & $\mathrm{Ni}$ & $\mathrm{Mg}$ \\
\hline AZ91D & 9.12 & 0.67 & 0.02 & 0.24 & 0.001 & 0.002 & 0.001 & bal. \\
\hline
\end{tabular}

Table 2 Bath composition for SAF.

\begin{tabular}{cl}
\hline \multicolumn{2}{c}{ Bath composition } \\
\hline $\mathrm{Na}_{2} \mathrm{O} \cdot \mathrm{SiO}_{2} \cdot 9 \mathrm{H}_{2} \mathrm{O}$ & $50 \mathrm{~g} / 1$ \\
\hline $\mathrm{KOH}$ & $50 \mathrm{~g} / 1$ \\
\hline $\mathrm{Na}_{2} \mathrm{CO}_{3}$ & $50 \mathrm{~g} / 1$ \\
\hline $\mathrm{Na}_{2} \mathrm{~B}_{4} \mathrm{O}_{7} \cdot 10 \mathrm{H}_{2} \mathrm{O}$ & $20 \mathrm{~g} / 1$ \\
\hline
\end{tabular}

Table 3 Anodizing conditions for SAF.

\begin{tabular}{cc}
\hline \multicolumn{2}{c}{ Anodizing condition } \\
\hline Current density & $3 \mathrm{~A} / \mathrm{dm}^{2}$ \\
\hline Temperature & $25^{\circ} \mathrm{C}$ \\
\hline Time & $1.8 \mathrm{ks}$ \\
\hline
\end{tabular}

formed using a hot chamber under the conditions of the mold temperature at 200 and injection rate at $2.6 \mathrm{~m} / \mathrm{sec}$ in dimensions of $\mathrm{W}: 70 \mathrm{~mm} \times \mathrm{L}: 150 \mathrm{~mm} \times \mathrm{t}: 3 \mathrm{~mm}$, and were cut into pieces $\mathrm{W}: 70 \mathrm{~mm} \times \mathrm{L}: 50 \mathrm{~mm} \times \mathrm{t}: 3 \mathrm{~mm}$ in size. The surface on one side of the specimen was prepared to a surface roughness of about $\mathrm{Ra}=1.0$ by using \#320 emery paper.

\subsection{Surface treatments}

\subsubsection{Chemical conversion, DOW17 anodizing and silicate-based anodizing}

As comparison treatments in this study, on the specimens described in 2.1, the MX3 chemical conversion (the primary process: ammonium hydrogen fluoride $50 \mathrm{~g} / \mathrm{L}$, the secondary process: sodium bi-chromate $120 \mathrm{~g} / \mathrm{L}$, potassium fluoride $2.5 \mathrm{~g} / \mathrm{L})$ which was considered suitable for corrosion resistance and a substrate treatment for the coating and which was described in JIS-H8651 and an anodizing treatment which contained hexavalent chromium and fluoride compounds and was well-known as DOW17 anodizing (ammonium hydrogen fluoride $250 \mathrm{~g} / \mathrm{L}$, sodium bi-chromate $100 \mathrm{~g} / \mathrm{L}$, phosphoric acid $90 \mathrm{ml} / \mathrm{L}$ ) were applied. And also, with reference to silicate-based anodizing, anodizing by the bath composition described in Tables 2 and 3 after weak alkaline cleaning was applied. In investigating the bath composition in this study, we used bath compositions of $50 \mathrm{~g} / \mathrm{L}$ each of potassium hydroxide, sodium silicate and sodium carbonate and $20 \mathrm{~g} / \mathrm{L}$ of sodium borate as the optimum bath composition, while the electrolysis condition was $3 \mathrm{~A} / \mathrm{dm}^{2}$ of current density and the treatment time was $1.8 \mathrm{ks}$. As the counter electrode, a carbon sheet was used.

\subsubsection{Cationic electrodeposition coating and organic spray coating}

After applying the substrate treatment shown in 2.2.1, cationic electrodeposition coating was performed. As this cationic electrodeposition coating, epoxy resin containing carbon black $(6 \mathrm{~g} / \mathrm{L})$ and in common industrial use was used.

The conditions of this cationic electrodeposition coating
Table 4 Conditions for cationic electrodeposition coating.

\begin{tabular}{cc}
\hline & Cationic electrodeposition \\
\hline Resin & epoxy \\
\hline Carbon black & $6 \mathrm{~g} / 1$ \\
\hline Temperature & $25^{\circ} \mathrm{C}$ \\
\hline Voltage & $60-100 \mathrm{~V}$ \\
& $\begin{array}{c}\text { for maintaining the } \\
\text { thickness at } 30 \mu \mathrm{m})\end{array}$ \\
\hline Time & $30 \mathrm{~s}$ \\
\hline Condition of heat treatment & $180^{\circ} \mathrm{C} \times 1.8 \mathrm{ks}$ \\
\hline Thickness & $30 \mu \mathrm{m}$ \\
\hline
\end{tabular}

are shown in Table 4. To ensure uniform thickness of electrodeposited film on each specimen, the weight change caused by electrodeposition coating was controlled to be equal. By this method, we assumed an equivalent weight of resin to be coated on each test specimen in theory, while the film thickness was about $30 \mu \mathrm{m}$ when calculated based on the surface area. As organic spray coating, the same substrate treatment was carried out, following which an epoxy-based primer spray coating was applied (heat treatment at $70^{\circ} \mathrm{C}$ for $1.2 \mathrm{ks}$ ), to which an acrylic finish spray coating was also applied (heat treatment at $165^{\circ} \mathrm{C}$ for $1.2 \mathrm{ks}$ ). The total film thickness of the primer and finish spray coatings was made to be $30 \mu \mathrm{m}$, the same as that of cationic electrodeposition coating.

\subsection{Characterization of coatings}

2.3.1 Surface roughness measurements and cross sectional images of electrodeposition coatings after various substrate treatments

By using a laser scanning microscope, the top surface was observed and the surface roughness with and without an electrodeposition coating on various substrate treatments were measured. As these substrate treated films with electrodeposited coatings do not transmit light, the results observed by the laser scanning microscope were adopted as the surface situation of the top surface.

\subsubsection{Cross sectional observation of SAF}

On SAF, its cross section was observed by SEM and the distribution state of the elements composed in the anodizing film was analyzed by EPMA.

\subsection{Evaluation of corrosion resistance \\ 2.4.1 Evaluation of the corrosion resistance of compo- site film on magnesium alloy}

After applying various substrate treatments, we applied electrodeposition coating or organic spray coating to them and compared their corrosion resistance. As the corrosion resistance test, the CASS Test stipulated in JIS H8681 was performed. The CASS Test is an accelerated corrosion test, used to evaluate the degree of rust formation by exposing test specimens exposed to a sprayed mist of acidic solution (pH 3.0), containing 5\% sodium chloride solution with cupric chloride and acetic acid, in a test chamber held at an atmospheric temperature of $50 \pm 2{ }^{\circ} \mathrm{C}$. Before this test, the test specimens were cross-cut (mesh size $1 \mathrm{~mm} \times 1 \mathrm{~mm}$ : 
$10 \times 10=100$ meshes) and the initial adhesion of the coatings before the CASS Test and after 6 cycles $345.6 \mathrm{ks}$ was evaluated by the Scotch Tape peeling test. Furthermore, cross-cut of $40 \mathrm{~mm}$ in length on other test specimens was made and the state of corrosion developed from the cross-cut part and the width and depth of corrosion by the CASS Test were evaluated. With reference to the corrosion width, the length of corrosion developed from the cross-cut part was measured by optical microscope. One cycle was taken at $57.6 \mathrm{ks}$ as 1 cycle and the degree of corrosion expansion was checked at each cycle, while and the test was applied a total of up to 6 cycles $345.6 \mathrm{ks}$. Moreover, to measure the corrosion depth, after the CASS Test, only the coating was peeled off and the corrosion by-products were removed by dipping it into a solution of $50 \mathrm{~g} / \mathrm{L}$ of chromic acid anhydride for 120 seconds. To measure the corrosion depth, since the dissolution amount of the magnesium of the matrix was in a negligible range after dipping it into chromic acid anhydride solution, we established the depth after dipping into chromic acid anhydride solution as the corrosion depth. The corrosion depth was measured using a laser scanning microscope and evaluated as the average corrosion depth and maximum corrosion depth after 6 cycles $345.6 \mathrm{ks}$.

\subsubsection{Electrochemical evaluation of films formed by} various substrate treatments

The corrosion resistances of films formed by various substrate treatments, such as DAF and SAF, were thought to be closely related to those of the composite film after coating, so DAF and SAF were evaluated electrochemically. The anodic and cathodic polarization curves of each substrate treatment were measured. Polarization measurement took place after immersion in a non-deaerated $5 \% \mathrm{NaCl}$ aqueous solution at $30^{\circ} \mathrm{C}$ for 900 seconds and at a sweep rate of $1 \mathrm{mV} /$ sec. As the reference electrode, an $\mathrm{Ag} / \mathrm{AgCl}$ electrode was used.

\section{Results and Discussion}

\subsection{Specimen appearance and top surface observation}

Figure 1 shows the images of the appearance after treatments by chemical conversion treatment, DOW17 anodizing and silicate-based anodizing described in 2.2.1. CCF charged dark brown, DAF was green, and SAF was white in color. After organic spray coating, no difference in appearance was observed on these different substrate treatments. However, the appearance of DAF with cationic electrodeposition coating was less glossy than the others; hence it seemed to provide low added value from the view point of design.

\subsection{Surface roughness measurement and cross-sectional images of electrodeposition coating after substrate treatment}

We investigated the difference in appearances after electrodeposition coatings on DAF and SAF, with the surface condition observed by a laser scanning microscope. The results are shown in Fig. 2. As shown in Fig. 2, the surface roughness was $\mathrm{Ra}=6.8$ and $\mathrm{Ra}=3.3$, on DAF and SAF, respectively, and these surfaces became rougher than the polished substrate with $\mathrm{Ra}=1.0$ before the treatment. By applying electrodeposition coating, the surface roughness of
SAF showed a tendency to become smoother from $\mathrm{Ra}=3.3$ to $\mathrm{Ra}=1.0$. In consideration of the fact that the top surface becomes smooth owing to thermal flow by fluidization phenomenon, and due to a decrease in the viscosity of electrodeposition coating resin at baking, we can consider the result of the decreased surface roughness to be quite reasonable. ${ }^{35)}$ However, in the case of DAF, the surface roughness did not decrease, but became from $\mathrm{Ra}=6.8$ to $\mathrm{Ra}=7.2$. No decrease in the surface roughness Ra was observed following application of electrodeposition coating on DAF. From these results, we found that the surface conditions differed widely, although the deposited resin amount was of equivalent weight to that on SAF. As we can see in the report by Ono et al. ${ }^{36)}$ they reported that on DAF, various sized voids and grain boundary cavities were observed and the film was grain deposits having a big crater structure void and granular structure. Moreover, compared with SAF, DAF is brittle, making it relatively difficult to cover the top surface in a good condition, due to the thermal flow effect caused by the resin amount; calculated based on only the apparent surface area alone. In other words, we presume it is hard to form the uniform resin layer on the top surface and the main part of the resin was used to fill the sparse part of DAF.

Figure 3 shows the cross sectional images of DAF and SAF with cationic electrodeposition coating. From these images, we can observe that the resin of the top surface of SAF with electrodeposition coating was smoothed by the thermal flow during the baking of electrodeposition coating. This matter corresponds to the fact that the top surface roughness, Ra, measured by the laser scanning microscope, decreased after electrodeposition coating. In the case of DAF, however, the top surface roughness, Ra, changed relatively little after electrodeposition coating was applied. Observing the cross section, the resin was deposited by filling the inside of the irregular and very sparse film, and the film formed by the resin on the top surface was thin. However, this variation did not cause any significant difference in the corrosion resistance, but only impacted on the gloss of the appearance.

\subsection{Cross-sectional structure analysis of SAF}

The area and point analyses on the cross section of SAF were applied by EPMA. The result of the area analysis on $\mathrm{Mg}, \mathrm{Si}, \mathrm{O}, \mathrm{K}, \mathrm{Al}, \mathrm{Na}$ and $\mathrm{Zn}$ as the elements possibly included in SAF is shown in Fig. 4 while the results of the point analysis are shown in Table 5. Based on the result of Xray diffraction described by our previous report, ${ }^{11)}$ the top surface layer was identified as $\mathrm{Mg}_{2} \mathrm{SiO}_{4}$. This result corresponds with that of the area analysis, and we can presume that the outer and inner parts of the film are composed of $\mathrm{Mg}_{2} \mathrm{SiO}_{4}$.

\subsection{Corrosion resistance evaluation of the magnesium alloy with the composite film}

For the initial adhesion of coating films, all 0/100 mesh was peeled off on all the test specimen, except the specimen with organic spray coating on DAF. For organic spray coating on DAF, however, an initial adhesive Scotch Tape peeling test was performed, with the result that 7 of 100 meshes peeled-off. For the majority of these peeled-off 


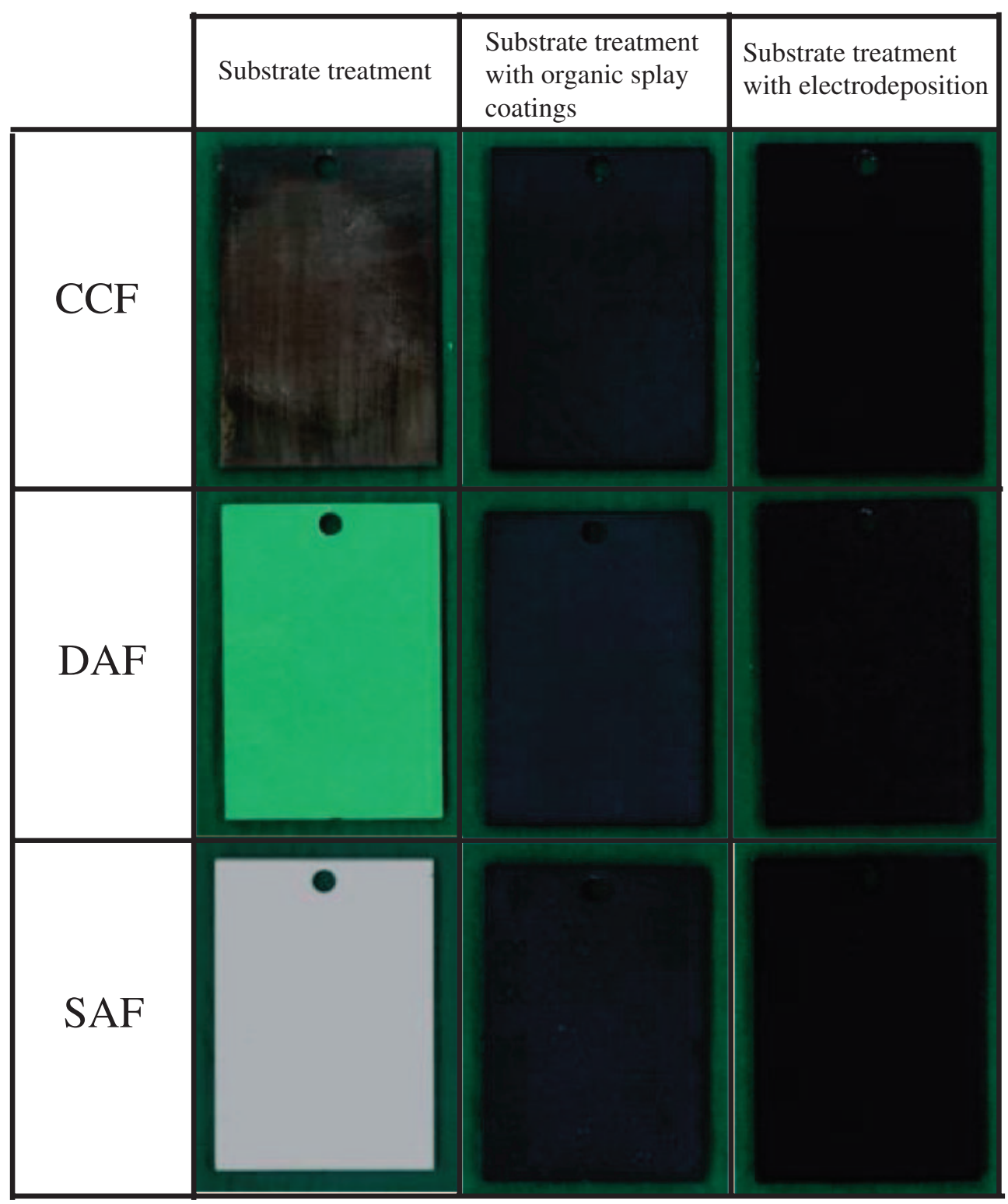

Fig. 1 Photographs of the surface appearance of specimens of each substrate treatment type after finished with organic spray coating or electrodeposition coating.

meshes, we confirmed that combined peeling-off occurred, whereby peeling-off occurred at the boundary of rganic spray coating and DAF, or the coagulation of DAF was destroyed. As a possible reason for this initial peeling-off, we can presume, based on the state of the combined peeling-off, the main cause to be the brittleness of the film. In the Scotch Tape peeling test after $345.6 \mathrm{ks}$ of the CASS Test, the peeling-off of the coating on all test specimens was not observed except for the initial peeling-off of DAF with organic spray coating. After $345.6 \mathrm{ks}$ ( 6 cycles) of the CASS test, the blister was formed in $38 / 100$ meshes on the specimen with electrodeposition coating on CCF and 15/100 meshes on the specimen with organic spray coating; namely, organic spray coating achieved a better result. Moreover, the blister was formed in $9 / 100$ meshes on the specimen with electrodeposition coating on DAF, and in 10/93 meshes on the specimen with organic spray coating. As for SAF, the blister was formed in $7 / 100$ meshes on the specimen with electrodeposition collating and in $6 / 100$ meshes on the specimen with organic spray coating, indicating that there was no significant difference in the formation ratio of blister between these coatings.

Figure 5 shows images of the corrosion described in the cross-cut area of CCF, DAF and SAF with electrodeposition and organic spray coating after $345.6 \mathrm{ks}$ ( 6 cycles) of the CASS test. The times of each CASS Test until the confirmation of the trace of corrosion, based on visual observation, were after $57.6 \mathrm{ks}$ on $\mathrm{CCF}$, after $115.2 \mathrm{ks}$ on DAF and after $172.8 \mathrm{ks}$ on SAF, respectively. As for the form of corrosion, the corrosion shape of CCF was filiform corrosion, and those of DAF and SAF were pitting corrosion. The average widths of the corrosion traces from the largest to the 5th one were applied for a comparison of corrosion resistance, with the result shown in Fig. 6. The corrosion width was larger on the speciments in the following order: $\mathrm{CCF}>\mathrm{DAF}>\mathrm{SAF}$ with both electrodeposition and organic spray coatings. On any substrate treatment, although the corrosion width increased with an increase in the CASS Test 


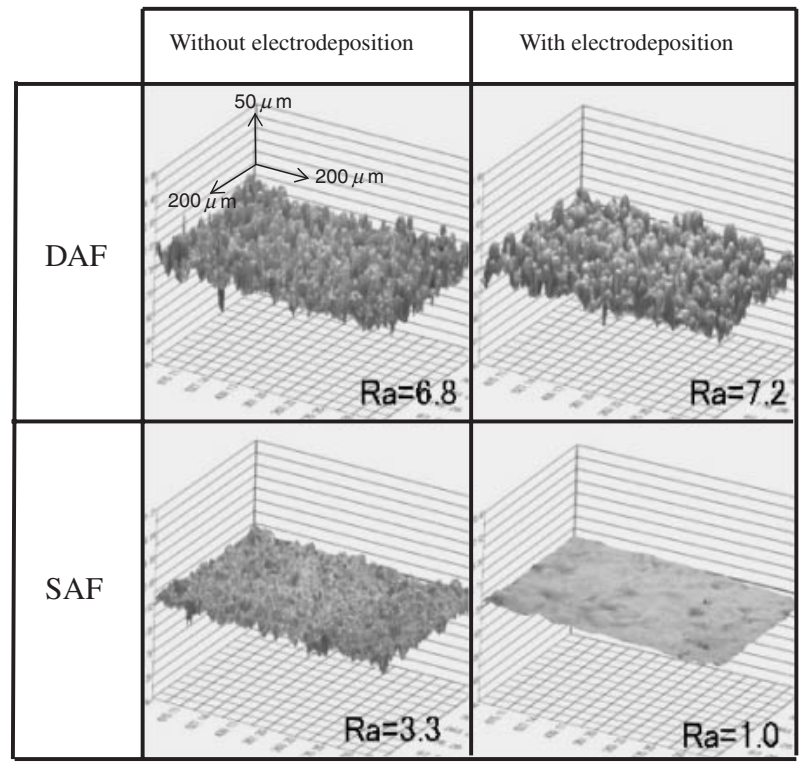

Fig. 2 The condition of the top surface of DAF and SAF with and without electrodeposition coating observed with laser microscopy.

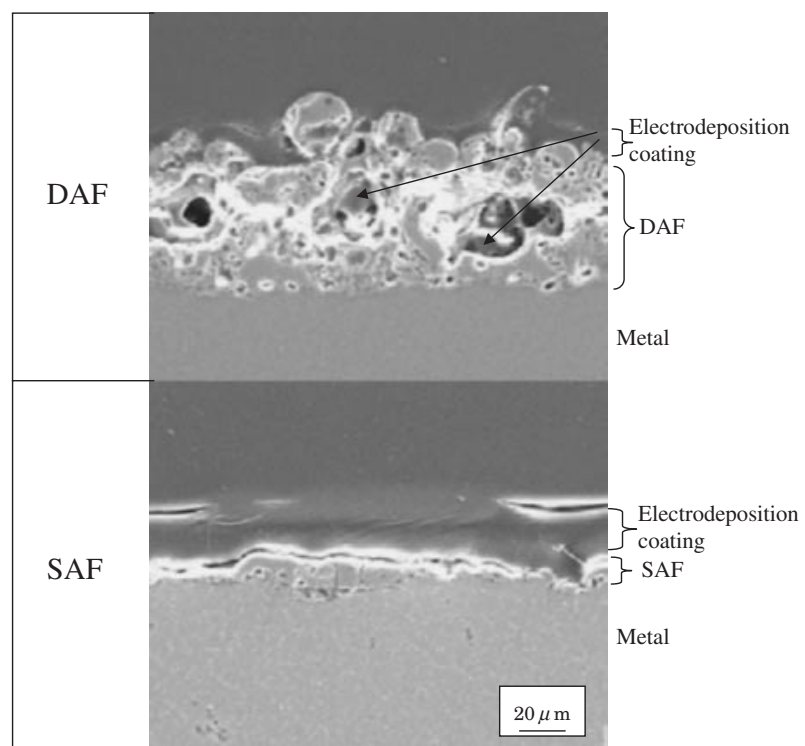

Fig. 3 SEM images of cross sections for DAF and SAF with electrodeposition coating.

time; the corrosion progress rate decreased with the increase of the CASS Test time. The corrosion width in the cross-cut area on the specimen of SAF with electrodeposition coationg was similar to that on the specimen with organic spray coating. Moreover, the corrosion width of SAF applied as the substrate treatment in this study was about $25 \%$ of that of CCF and about $60 \%$ of DAF, respectively.

Therefore, the corrosion depths were also measured and the results are shown in Fig. 7. During the same procedure with corrosion width measurement, the average depth of the corrosion traces, from the largest to the fifth largest corrosion, were measured, and the average of each depth and the maximum depth respectively were used to evaluate the corrosion resistance. As each corrosion trace had a complicated three dimensional shape, the average and maximum

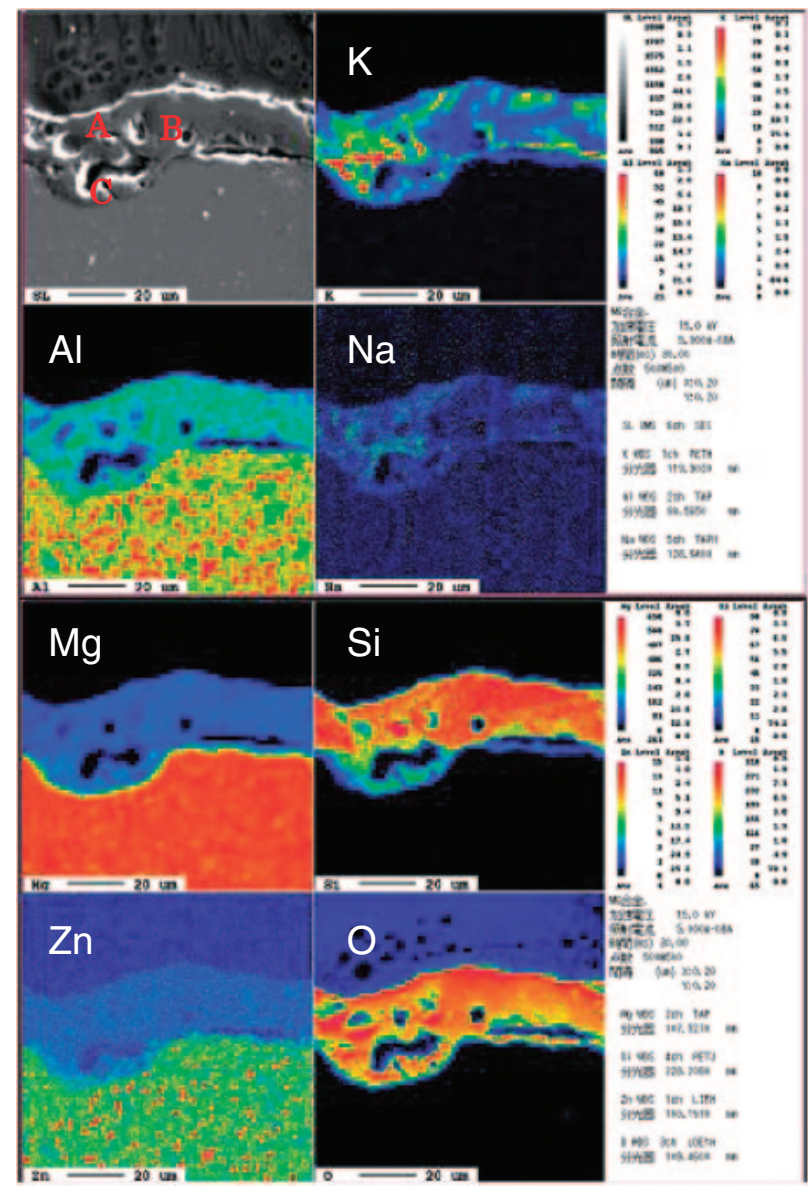

Fig. 4 Area analysis for the cross sections of SAF by EPMA.

Table 5 Point analysis results at selected points on SAF by EPMA.

\begin{tabular}{crrr}
\hline At\% & \multicolumn{1}{c}{ A } & \multicolumn{1}{c}{ B } & \multicolumn{1}{c}{ C } \\
\hline $\mathrm{O}$ & 77.5 & 76.7 & 77.1 \\
$\mathrm{Na}$ & 1.2 & 0.8 & 0.5 \\
$\mathrm{Mg}$ & 9.6 & 10.6 & 15.8 \\
$\mathrm{Al}$ & 1.1 & 1.3 & 2.6 \\
$\mathrm{Si}$ & 7.7 & 9.7 & 3.4 \\
$\mathrm{~K}$ & 2.9 & 0.9 & 0.6 \\
\hline
\end{tabular}

corrosion depths showed significantly different values. From Fig. 7, we noted a trend whereby the corrosion depth of electrodeposition coating appeared shallower than that of organic coating in the case of the same substrate treatment. Moreover, although the chemical treatment showed the highest figure in terms of corrosion width, in the case of the corrosion depth, it was lower than DAF and at the same level or lower than SAF. Judging from the ratio of the corrosion widths and depths shown in Fig. 6 and Fig. 7, we found that the corrosion of the specimen with CCF was wider and shallower than those with DAF and SAF, indicating that it proceeded in a horizontal direction like a filiform corrosion. On the other hand, in the case of DAF and SAF, the corrosion width was narrow but the corrosion depth was deep, indicating that the corrosion proceeded in a vertical direction like pitting corrosion. 


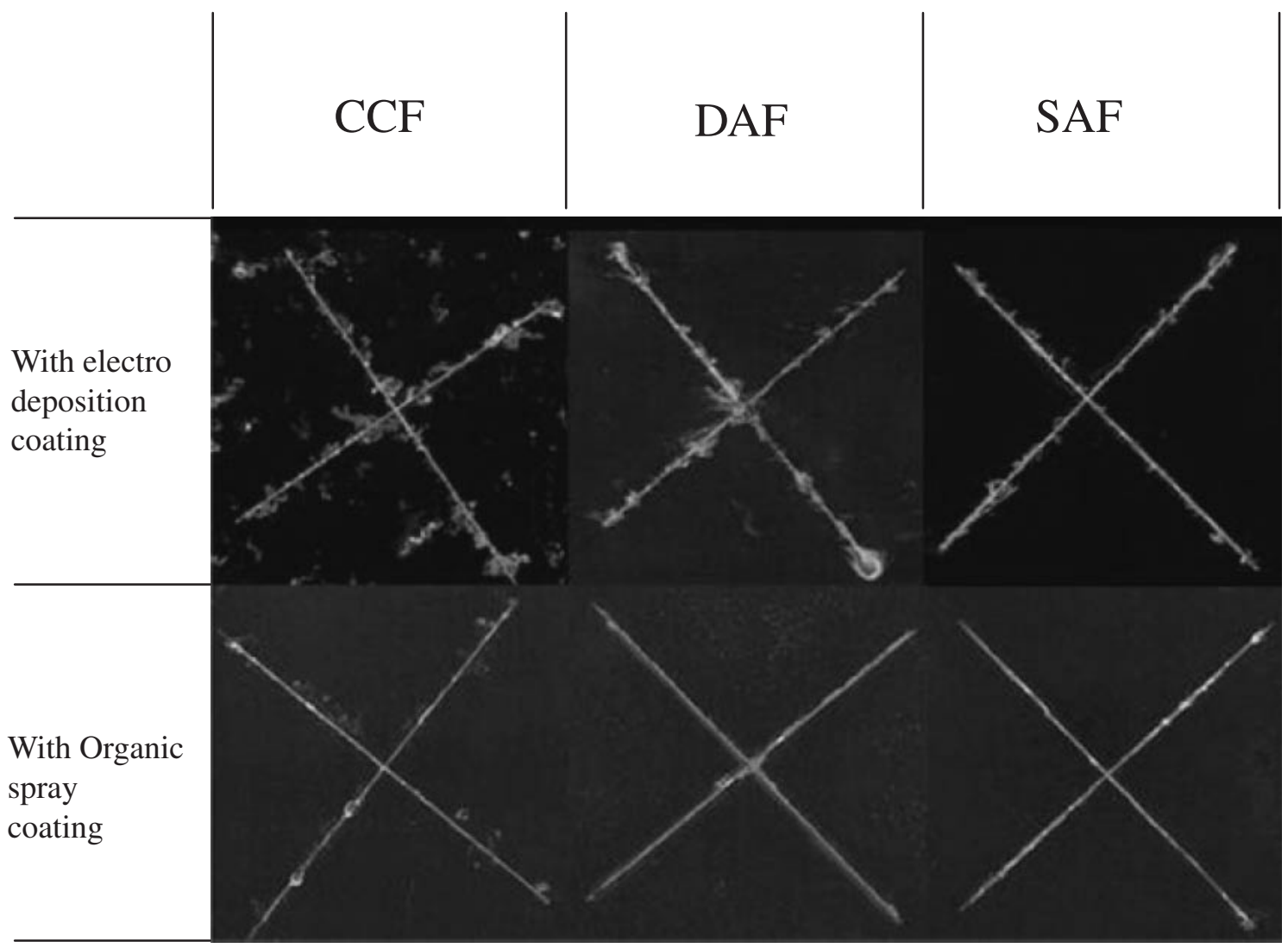

$10 \mathrm{~mm}$

Fig. 5 Corrosion in cross-cut area of electrodeposition coated surfaces and organic spray-coated surfaces after 6 cycles in CASS testing.

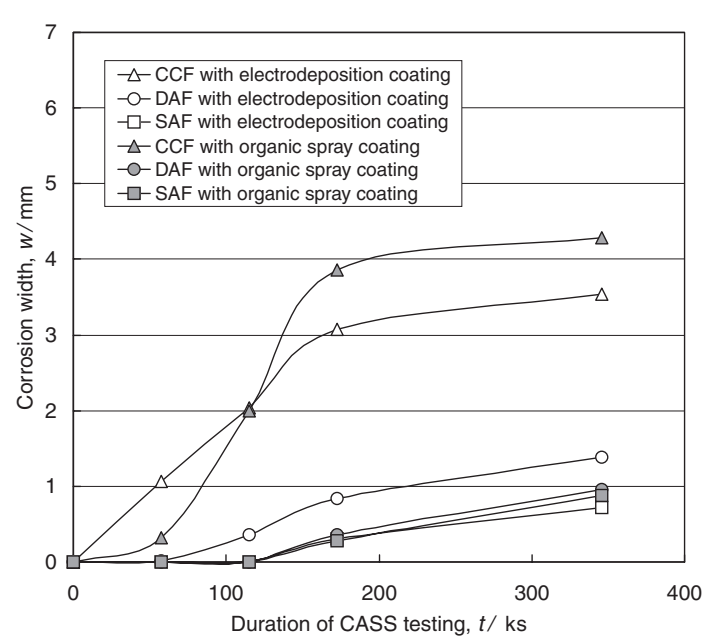

Fig. 6 Corrosion width in cross-cut area on the surfaces with organic spray coating and electrodeposition coating after 6 cycles in CASS testing.

\subsection{Electrochemical evaluation of various substrate treatments}

Though we can highlight the corrosion resistance and adhesion of electrodeposition coating itself as a factor of the corrosion resistance of the composite film of anodizing and electrodeposition coating, it is also largely dependent on the corrosion resistance of the anodizing film of the substrate treatment. Therefore, a comparison of the corrosion resistance was performed electrochemically by measuring the

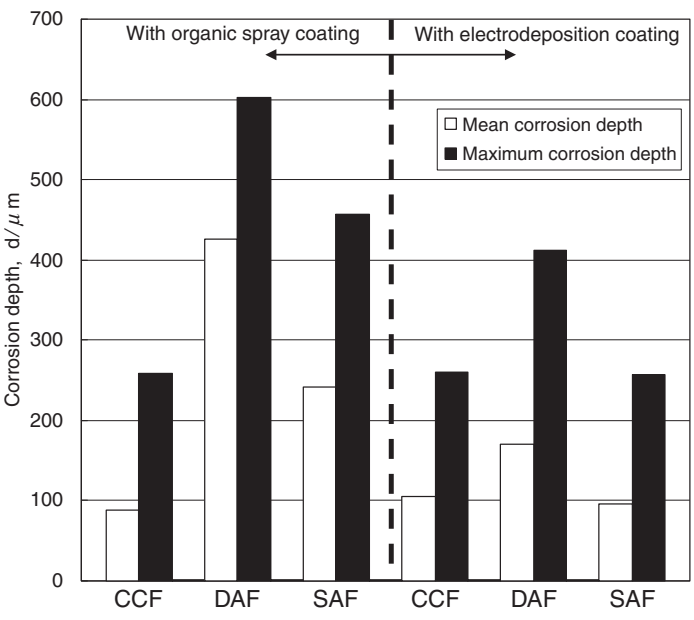

Fig. 7 Corrosion depth in cross-cut area on the surfaces with organic spray coating and electrodeposition coating after 6 cycles in CASS testing.

polarization of each anodizing film. These results are shown in Fig. 8.

In the polarization curve, the current density of the specimen of DAF is higher than that of the specimen of SAF by almost 2 digits as you can see. As a result, we consider the corrosion resistance of latter was higher than that of the former.

Judging from the cause of the high anodic current density of the specimen of DAF, the anodic current density of DAF 


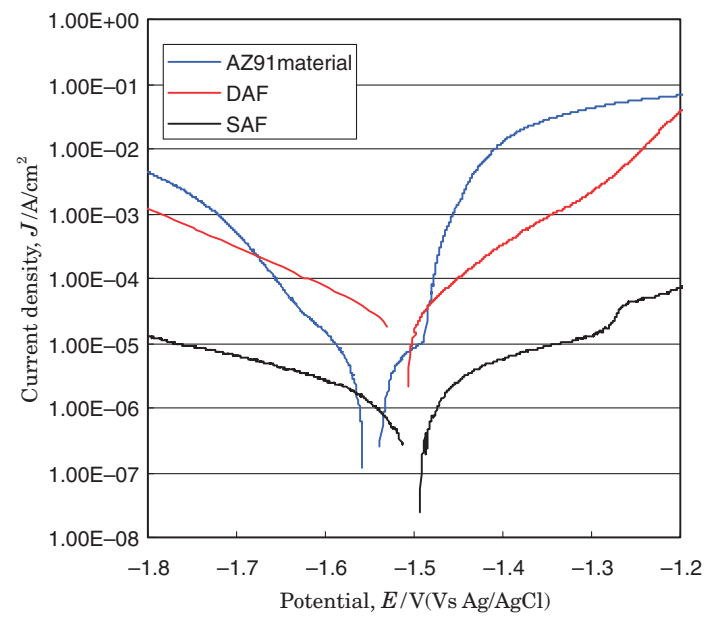

Fig. 8 Polarized curves for AZ91, DAF and SAF.

seemed to become high, indicating the true reacting surface area of DAF was wide, because of the high cathodic current density and the large surface roughness of DAF. Furthermore, DAF is thought to be composed of inorganic materials as its main components, such as $\mathrm{Cr}_{2} \mathrm{O}_{3}, \mathrm{MgF}_{2}$ and $\mathrm{MgF}_{2}$ is considered as electrolyte film containing ion crystals. ${ }^{21)}$ On the other hand, the main component of $\mathrm{SAF}$ is $\mathrm{Mg}_{2} \mathrm{SiO}_{4}$, which seems to be electrically stable.

Based on these results, we found that the composite film of SAF with cationic electrodeposition coating in this study, which does not use chromium, phosphorus and fluorine and the water base electrodeposition coating applicable to VOC regulations to be extremely effective.

\section{Conclusions}

In this study, as the substrate treatment of coating on the AZ91D die-casting substrate, we applied conventional DAF (DOW17 anodized film) and CCF (chemical conversion treatment JISA3-type MX3 film), which contained hexavalent chromium, fluorine and phosphorus compounds, in order to compare with environmentally friendly SAF (silicate anodized film) with no hazardous substances. And to these substrate treatments, we applied a water-based cationic electrodeposition coating which had a good uniform coating effect, on even complicated shapes, and was applicable to VOC regulations in order to compare with organic spray coating. From the investigation of the corrosion resistance of these films from the result of CASS Test and electrochemical perspective, we reached the following conclusions:

(1) In the case of the application of organic spray coating on $\mathrm{CCF}$, DAF and SAF, the three composite films all exhibited the same appearance; however, in the case of the application of the cationic electrodeposition coating, DAF showed a rougher surface and less gloss compared with SAF, so it seemed to be a lower added value in design. This is because the film is very sparse, so we think that the surface roughness is not recovered completely, even after cationic electrodeposition coating.

(2) Based on the result of the cross-cut test with the CASS Test, as the initial adhesion, the number of specimens peeledoff was zero on 100 meshes except organic spray coating on
DAF. On organic spray coating on DAF, 7 of 100 meshes were peeled-off.

(3) Based on the observation of corrosion from the cross-cut area of the composite film after the CASS Test, the corrosion shape at the cross-cut part of the composite of CCF was filiform corrosion and blister, while on the other hand, that of DAF and SAF was pitting corrosion. The times which we could confirm the formation of the corrosion trace by visual means were $57.6 \mathrm{ks}$ on the composite of CCF, $115.2 \mathrm{ks}$ on the composite of DAF and $172.8 \mathrm{ks}$ on the composite of SAF, respectively. In the case of on SAF with cationic electrodeposition coating in this study, the evaluation value of the corrosion width at the cross-cut area after $345.6 \mathrm{ks}$ ( 6 cycles) of the CASS test was about $25 \%$ of the specimen with CCF and about $60 \%$ of the specimen with DAF, respectively. The corrosion depth of the specimen with SAF was shallower than that with DAF while the corrosion width of the former was similar to that of the latter.

(4) Based on the measured results of the polarization curve, the corrosion resistance of SAF itself is superior to that of DAF.

(5) Based on these test results, we found that the composite film of SAF with cationic electrodeposition coating in this study which did not contain any hazardous substances such as chromium, phosphorus, fluorine and others was applicable to VOC regulations and had not only high corrosion resistance but also brightness. As a result the composite film of SAF with cationic electrodeposition coating is an extremely useful surface treatment for a magnesium alloy.

\section{REFERENCES}

1) The Japan Institute of Light Metals: Study of Light Metals and History of the Technology, (the japan institute of light metals, Japan, 1991) pp. 172-175.

2) H. Kambe, T. Koike and M. Sasajima: In the Forefront of Molding Processing Technology for Magnesium Alloy, (CMC publishing, Japan, 2005) pp. 255-281.

3) F. Sato, Y. Asakawa, T. Nakayama and H. Sato: J. JILM. 42 (1992) 752-758.

4) R. Morita, H. Kaneko and K. Oshita: J. JILM. 50 (2000) 560-566.

5) S. Matsuda: The Latest Surface Treatment Technology for Magnesium Alloy: Present and Future, The Japan Magnesium Association (2003) pp. 59-62.

6) M. Walter and P. Kurze: SAE Technical Paper (2004) 2004-01-0134.

7) H. Nakada, K. Otomi and K. Yamaguchi: Journal of the Surface Finishing Society of Japan 55 (2004) 715-71821.

8) K. Ashida: Corrosion Behaviors of Magnesium Alloy, The Japan Magnesium Association (2005) pp. 36-39.

9) M. Weiner: Metal Finishing 7 (1995) 65-67.

10) G. G. Wang, K. Stewart, R. Berkmortel and J. L. Skar: SAE Technical Paper 421 (2001) 1.

11) M. Hara, K. Matsuda, W. Yamauchi, M. Sakaguchi, T. Yoshikata, Y. Takigawa and K. Higashi: Mater. Trans. 47 (2006) 1013-1019.

12) K. Maeda: The Industrial Coating 128 (1994) 30-36.

13) H. Taniguchi and M. Taguchi: The Industrial Coating 108 (1991) 4753.

14) M. Mizokawa: The Industrial Coating 112 (1991) 35-45.

15) R. Murakami: Journal of The Surface Finishing Society of Japan $\mathbf{5 3}$ (2002) 288-292.

16) J. H. Nordlien, S. Ono, N. Masuko and K. Nisancioglu: Corrosion Science 39 (1997) 1397-1414.

17) J. H. Nordlien, K. Nisancioglu, S. Ono and N. Masuko: J. Electrochemical Society 143 (1996) 2564-2572.

18) S. Ono, K. Asami, T. Osaka and N. Masuko: J. Electrochemical Society 
143 (1996) L62-63.

19) S. Ono, K. Asami and N. Masuko: Mater. Trans. 42 (2001) 1225-1231.

20) S. Ono: Journal of the Japanese Anodizing Association 5 (2002) 42-49.

21) S. Ono: Journal of the Surface Finishing Society of Japan 53 (2002) $166-171$

22) Y. Mizutani, S. J. Kim, R. Ichino and M. Okido: Surface and Coatings Technology 169 (2003) 143-146.

23) H. Y. Hsiao and W. T. Tsai: Corrosion 2003 paper 03212.

24) S. Ono: Journal of Surface Science 19 (1998) 790-798.

25) C. Blawert, V. Heitmann, W. Dietzel, H. M. Nykyforchyn and M. D. Klapkiv: Surface and Coatings Technology 200 (2005) 68-72.

26) H. Y. Hsiao, H. C. Tsung and W. T. Tsai: Surface and Coatings Technology 199 (2005) 127-134.

27) Y. Zhang, C. Yan, F. Wang, H. Lou and C. Cao: Surface and Coatings Technology 161 (2002) 36-43.

28) Q. Cai, L. Wang, B. Wei and Q. Liu: Surface and Coatings Technology
200 (2006) 3727-3733.

29) Y. Wang, J. Wang, J. Zhang and Z. Zhang: Mater. Corros. 56 (2005) 88-92.

30) P. N. Ross, J. A. MacCulloch, G. A. Wright, E. A. Carter and T. F. Barton: SAE Technical Paper (1998) 980088.

31) J. E. Gray and B. Luan: J. Alloy. Compd. 336 (2002) 88-113.

32) M. Takaya, T. Itoh and H. Umehara: J. JILM. 42 (1992) 784-789.

33) H. Umehara, M. Takaya and T. Itoh: J. JILM. 48 (1998) 248-255.

34) N. Hara, Y. Kobayashi, D. Kagaya and N. Akao: Corrosion Science 49 (2007) 166-175.

35) T. Nakamichi: Journal of the Japan Society of Colour Material 51 (1978) 528-541.

36) The Japan Magnesium Association: A Comprehensive Reference Guide to Magnesium Technology, (Kallos Publishing, Japan, 2000) pp. 335346. 